\section{Exploring Ways to Enhance Student Learning During Study Abroad: Landscape Exploration of Brazil}

\author{
Susan Barton ${ }^{1,2}$, Jules Bruck ${ }^{1}$, and Chad Nelson ${ }^{1}$
}

ADDITIONAL INDEX WORDs. teaching, experiential, observational skills, reflection, blogs, cultural experiences, evaluation

Summary. A study abroad trip to Brazil was conducted by the University of Delaware's Department of Plant and Soil Sciences in Jan. 2008 to study diverse ecosystems in three major regions: Mata Atlantica (Atlantic forest), Pantanal (wetland), and Amazon (rain forest). Students spent time in Cuiaba, Manaus, Brasilia, and Rio de Janeiro, Brazil. Different garden styles were studied throughout Brazil. Student learning occurred through student presentations, blog assignments, site visits, interaction with local contacts, observational exercises, reflection exercises, immediate feedback assessment test quizzes, cultural experiences, and a culminating project. Thirteen students attended the program with three faculty directors. Two courses were offered: Field Sketching of Landscape Subjects (PLSC 167) and Arts and Ecosystems (PLSC 267). Class goals were to understand the differences between ecosystems within Brazil and more familiar ecosystems in the mid-Atlantic United States; to learn how natural ecosystems inspire landscape design; and to become aware of major environmental issues in Brazil. An effective study abroad program not only exposes students to unique experiences, but also helps students use those experiences to change their perspectives and understanding. Because of the variety of human learning styles, offering a range of educational activities is important so that all students have an opportunity to respond favorably.

0 tudy abroad programs vary widely in their academic rigor. The goal of an effective study abroad program is to overcome the "on vacation" factor and to provide students with an opportunity to study relevant topics in a different culture, rather than to simply tour interesting sites (Andrews and Henze, 2009). In Spring 2006, three faculty members in the University of Delaware's (UD) Department of Plant and Soil Sciences began planning for a new study abroad program entitled "Landscape Exploration of Brazil." The program was accepted and offered during winter session 2008 (2 Jan.-2 Feb.).

The objectives of this article are to use student performance, student evaluations $(\mathrm{n}=9)$, and faculty evaluations to analyze study abroad teaching methods. Then, based on qualitative data, we suggest the most effective components for enhancing student learning during a plant science study abroad program.

\section{Course overview}

Thirteen students (eight plant and soil science students, two

${ }^{1}$ University of Delaware Coop Extension, Townsend Hall, 531 S. College Avenue, Newark, DE 19717

${ }^{2}$ Corresponding author. E-mail: sbarton@udel.edu. students from other majors in the College of Agriculture and Natural Resources, two students with unrelated majors, and one continuing education student) attended the program with three faculty members from the UD Department of Plant and Soil Sciences. Two courses were offered: Field Sketching of Landscape Subjects [Plant and Soil Sciences (PLSC) 167] and Arts and Ecosystems (PLSC 267) (Table 1). These courses were team taught.

The experience began with $11 \mathrm{~d}$ in Rio de Janeiro, Brazil, followed by and Brasilia, Brazil. For the last $7 \mathrm{~d}$, the students returned to Rio de Janeiro. Students studied diverse ecosystems in three major regions of Brazil: Mata Atlantica (Atlantic forest), Pantanal (wetland), and Amazon (rain forest). Students also visited gardens throughout Brazil to compare and contrast garden styles and to learn firsthand how natural areas inspire design. In Rio de Janeiro, the art and landscape designs of Roberto Burle Marx were analyzed by visiting public and private gardens and public parks, and by meeting with landscape architects from Burle Marx \& CIA LTDA (Rio de Janeiro, Brazil). a 13-d excursion to Cuiaba, Manaus,
Ecosystems of the Mata Atlantica were observed by visiting Tingua Forest and Tijuca Forest. From Cuiaba, Brazil, students and faculty traveled to the Pantanal, which is the largest remaining wetland in the world. The Instituto Nacional de Pesquisas da Amazônia (INPA) research facility (Manaus, Brazil) and a 3-d river cruise on the Rio Negro and the Rio Salimoes provided an opportunity to study the Amazon forest ecosystem. Students and faculty toured the ensemble of civic buildings designed by modernist architect Lúcio Costa and gardens designed by Roberto Burle Marx in the capital city of Brasilia, Brazil.

\section{Preprogram preparation}

A variety of students with different levels of horticultural knowledge participated in this study abroad program. Preprogram preparation during the semester was intended to provide students with enough knowledge of forest ecosystems of the midAtlantic United States and the design legacy of Burle Marx to help students achieve the course learning objectives (to compare forest ecosystems in Brazil to forest ecosystems in the mid-Atlantic United States and to understand how natural ecosystems inspire design). Predeparture preparation included two regional field trips (Longwood Gardens, Kennett Square, PA and Ashland Hollow, Hockessin, DE), required reading assignments, and a predeparture meeting. In preparation for the trip to Longwood Gardens, students were given an article "Art Meets Nature in Pierce's Woods" (McIntyre, 2006), which highlights landscape architect W. Gary Smith's approach to Pierce's Woods and connects to the works and practices of Burle Marx. At Longwood Gardens, students observed moderately managed woodlands that realistically reflect the pressures of invasive plant species, deer browse, and successional forces. They also observed Pierce's Woods (designed naturalistic garden in Longwood Gardens inspired by Burle Marx) and the Cascade Room (garden in Longwood Gardens' conservatory designed by Burle Marx in 1993 using bold tropical plants on horizontal and vertical surfaces). Students visited nearby Ashland Hollow, a private garden developed and owned by landscape architect Bill Frederick. 
Table 1. Course content offered in the University of Delaware study abroad program "Landscape Exploration of Brazil."

\begin{tabular}{|c|c|c|}
\hline $\begin{array}{l}\text { Course } \\
\text { title }\end{array}$ & $\begin{array}{c}\text { Arts and Ecosystems } \\
\text { [Plant and Soil Sciences (PLSC) 267] }\end{array}$ & $\begin{array}{c}\text { Field Sketching } \\
\text { of Landscape Subjects (PLSC 167) }\end{array}$ \\
\hline Course description & $\begin{array}{l}\text { Students will learn about Brazilian design, culture, } \\
\text { and ecological systems contrasted with familiar } \\
\text { materials from home. Students will learn } \\
\text { to document places with spatial accuracy while } \\
\text { traveling. Students will chose from selected sites } \\
\text { to develop a landscape design proposal in Brazil } \\
\text { that will be informed by program travel. Field } \\
\text { visits will be incorporated into the course structure. } \\
\text { Students will develop proposals that promote } \\
\text { sustainable design. }\end{array}$ & $\begin{array}{l}\text { This course will focus on sketching } \\
\text { techniques needed to portray } \\
\text { landscape subjects. Students will } \\
\text { learn a variety of techniques } \\
\text { designed to build confidence } \\
\text { and document their journey } \\
\text { through Brazil. }\end{array}$ \\
\hline Lectures/exercises & $\begin{array}{l}\text { Ecosystem lectures: } \\
\text { - The world of plants } \\
\text { - Invasive plants } \\
\text { - Mata Atlantica } \\
\text { - Conservation vs. colonialism } \\
\text { Design lectures: } \\
\text { - Design basics } \\
\text { - Sense of place } \\
\text { - Patterns in the landscape } \\
\text { - Music and design } \\
\text { - Art in the landscape } \\
\text { Cultural lectures: } \\
\text { - Brazil basics } \\
\text { - Culture and Brazilian food } \\
\text { - Burle Marx: The man } \\
\text { - Modern architecture in Brasilia } \\
\text { - Brasilia and Washington, DC comparison }\end{array}$ & $\begin{array}{l}\text { Observational exercises: } \\
\text { - Subject observation } \\
\text { - Sentence add-on } \\
\text { - Copy standard item } \\
\text { - Quick sketches } \\
\text { - Field notes } \\
\text { Sketching technique exercises: } \\
\text { - Gesture } \\
\text { - Positive/negative space } \\
\text { - Scaling } \\
\text { - Gradation of tone } \\
\text { - Tone at different times } \\
\text { - Individual leaves to full tree } \\
\text { - Ink } \\
\text { - One-point perspective } \\
\text { - Two-point perspective }\end{array}$ \\
\hline Time allocated & $\begin{array}{l}\text { Each lecture was about } 1 \mathrm{~h} \text { and was conducted } \\
\text { in a modified classroom space. }\end{array}$ & $\begin{array}{l}\text { Sketching exercises varied from } \\
30 \text { min to } 1 \text { h and were } \\
\text { conducted at site visits } \\
\text { throughout program. }\end{array}$ \\
\hline
\end{tabular}

Contemporaries of Burle Marx, Bill and Nancy Frederick, included biomorphic masses of plants and abstracted pool forms that are a synthesis of Burle Marx approaches within the regional vernacular of rural Delaware.

A final meeting was held on campus at the end of the fall semester to share and review logistical details of the upcoming travel with students and their parents and to participate in icebreaking and team-building exercises. One useful preparatory exercise was sharing childhood memories of places where the students had found an early connection to the natural world. The topic built on a theme established by the required reading of the prologue of Robert Michael Pyle's book “The Thunder Tree: Lessons from an Urban Wildland" (Pyle, 1993). The prologue discusses how individuals can discover their own connection to the natural world through everyday places that are not necessarily grand or designed.
Although each of the predeparture components was considered useful by the faculty directors, some improvements can be suggested. First, participation was difficult to coordinate with student schedules. One solution would be the creation of a one-credit required course in the semester preceding the program. Other faculty members have expressed the need to conduct class sessions before the study abroad program to prepare students and to provide time to cover sufficient course content (Andrews and Henze, 2009). Student evaluations indicated that many $(78 \%)$ felt unprepared for their experiences in Brazil (Table 2).

\section{Student learning}

Instructional techniques used to enhance student learning included student presentations, blog assignments, site visits, interaction with local contacts, observational exercises, reflection exercises, immediate feedback assessment tests (IFAT), a culminating project, and cultural experiences. Nine students completed an online evaluation of this study abroad program as administered by the UD Center for International Studies. Techniques listed will be described and assessed based on quantitative (Table 2 ) and qualitative measures from student evaluations (Table 3) and faculty director evaluation.

Student PRESEnTATION. A particularly effective aspect of the program was having one student conduct research before the program so as to deliver a lecture on the architecture of Brasilia, a teaching technique with proven learning outcomes (Andrews and Henze, 2009). This student had a special interest in the modern architecture movement in Brazil of the 1950 s and 1960s; therefore, the student was eager to learn about the social and political forces that shaped what can be seen today. We recommend providing students with a list of pertinent topics from which they can 
select in the semester preceding departure, culminating in an in-country presentation to the rest of the group.

Blog assignment. Blogs help students collect and chronicle diverse evidence/learning experiences from diverse points of view (Kozlek, 2008). The UD Office of Student Affairs provides a video camera to create video clips for inclusion in a blog. Our Landscape Exploration of Brazil blog served as a record of the program through photographs, text, and videos (Landscape Exploration of Brazil, 2008). Friends and family found the blog to be the most reliable and cost-effective way to get updates on the program, but blogging was inconsistent and authored by only a few students. On-site blogging could be improved by developing a routine process for transferring digital photographs to the blog site, incorporating blog assignments into the curriculum so there is shared student responsibility for maintaining the blog, and having each student create a blog entry before departure while university technical support and equipment are easily available.

SITE visits. The program included visits to a number of sites in Brazil, including Sitio Roberto Burle Marx (the studio, home, and garden of Burle Marx in Rio de Janeiro), Magalhaes Residence (a private garden in Rio de Janeiro designed by Burle Marx and Haruyoshi Ono),

Table 2. Quantitative measures of student learning during "Landscape Exploration of Brazil" study abroad program as expressed in student quotes on University of Delaware Center for International Studies study abroad evaluations $(\mathbf{n}=9)$.

\begin{tabular}{lc}
\hline Student responses & Students (\%) \\
\hline $\begin{array}{l}\text { Felt unprepared for their experiences in Brazil } \\
\text { Struggled to make the connection }\end{array}$ & 78 \\
$\quad$ between site visits and lectures & 44 \\
Perceived Plant and Soil Sciences (PLSC) 167 as more & \\
$\quad$ connected than PLSC 267 to site visits & 55 \\
Wanted more time to complete the culminating project & 44 \\
\hline
\end{tabular}

Flamingo Park (a public park in Rio de Janeiro designed by Burle Marx), the Ministry of Health roof garden (a garden on a public building in Rio de Janeiro designed by Burle Marx), the Modern Museum of Art (Rio de Janeiro), Tijuca Forest (Rio de Janeiro), Tingua Forest (Nova Iguaçu), the INPA research facility (Manaus), and Palace d'Imartay (a government building in Brasilia with Burle Marx gardens). These sites were selected for their potential contribution to students' understanding of art, ecosystems, and sketching. In some cases, the connection to course content was obvious, but some students $(44 \%)$ struggled to make the connection between site visits and lectures (Table 2).

Field Sketching of Landscape Subjects (PLSC 167) was perceived by students $(\mathbf{5 5 \%})$ as more connected than Arts and Ecosystems (PLSC 267) to site visits (Table 2), and landscape sketching exercises were conducted at most sites visited. When structuring a study abroad program, faculty must evaluate each site visit/ excursion and include an exercise to allow students to digest what they learn at that site. For example, at the Modern Museum of Art, students

Table 3. Qualitative measures of student learning during "Landscape Exploration of Brazil” study abroad program as expressed in student quotes on University of Delaware Center for International Studies study abroad evaluations $(\mathbf{n}=9)$.

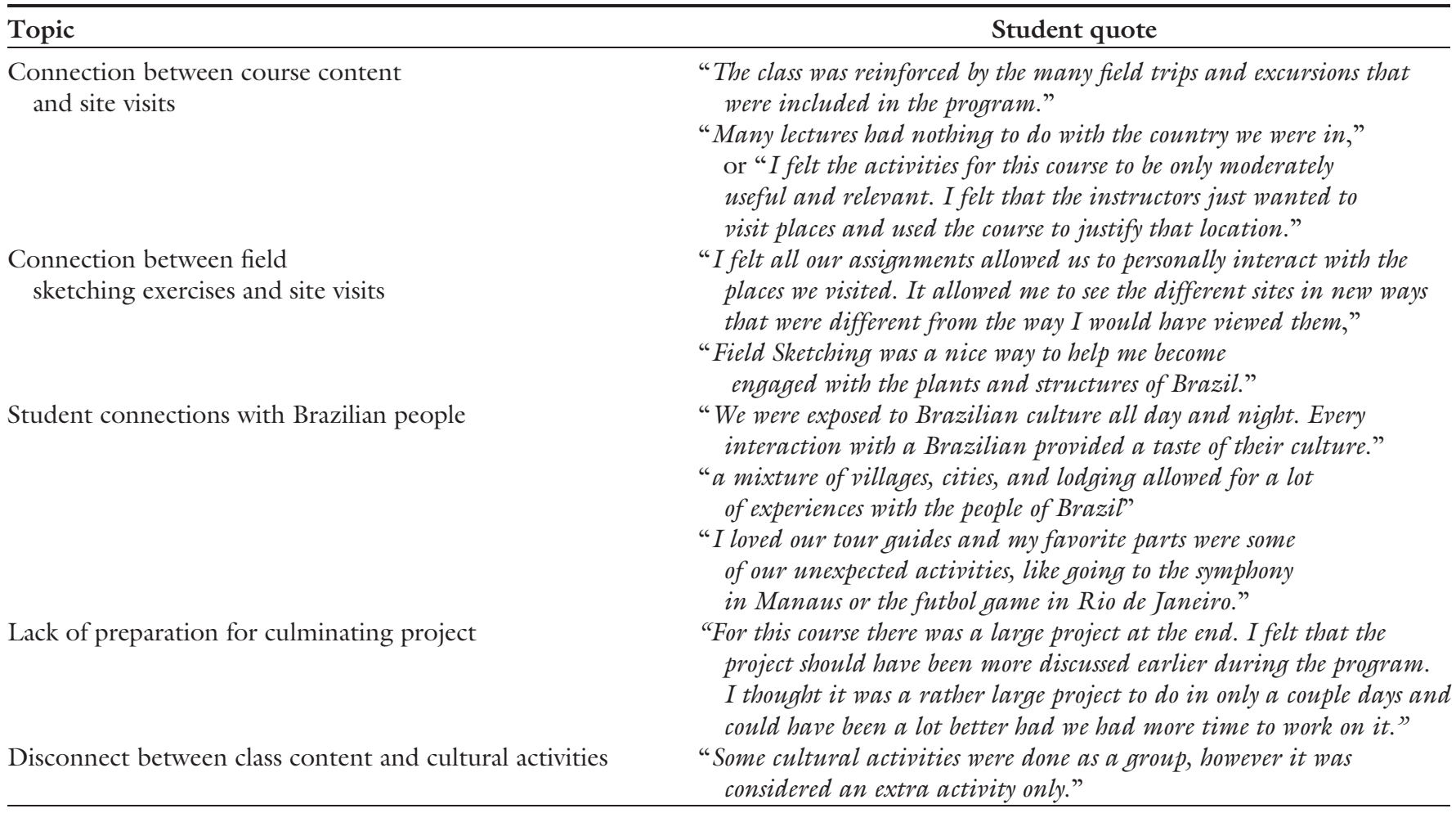


were asked to individually observe all the exhibits. After $1 \mathrm{~h}$ of observation, the class and each student shared and explained the exhibit he or she thought was most meaningful in promoting a deeper exploration of the experience.

At the Magalhaes Residence, several design principles were discussed, including the use of color, line, and the creation of space. This visit could have been more meaningful if a design lecture had preceded the visit. Students could participate in a debriefing session at the end of the site visit to share lecture-based examples. Students could then be asked to document their landscape example photographically or by sketching to create a new design principle presentation based on the combined student examples. When site visits include a specific, bounded exercise that pertains to course content, students become engaged (Andrews and Henze, 2009). This strategy follows Kolb's "learning cycle" model: experience an environment, reflect on that experience, and finally, analyze the experience according to new concepts taught in the course (Montrose, 2002).

Local contacts. One of the goals of a study abroad program is to expose students to cultural aspects of a foreign country, and students in the Landscape Exploration program enjoyed this diverse cultural immersion and the knowledge that the variety of destinations added to their experience of Brazilian culture (Table $3)$. Our connection to Brazilians started in the United States when we met a Brazilian student who was studying English at UD. He joined the class on the preprogram field trips, helped negotiate hotel accommodations (in Portuguese), and joined the group in Brasilia, Brazil. He had never visited his country's capital city and our students benefited from exploring through the eyes of a Brazilian who shared many perspectives of his government. Faculty directors should look to their own university community for resource people who could add such value to their programs before, during, and/ or upon return.

The program included an array of experiences, most of which were facilitated by local guides, who certainly heightened the learning opportunities. Local guides provided valuable background information, allowing faculty to focus on their course work. Personal connections, such as evenings at Canto do Arancua lodge spent playing guitar, singing, and conversing around a campfire brought the culture of Brazil to life for the students. Faculty must work closely with guides to structure effective site visits and maximize the learning experience.

ENHANCING OBSERVATION. "Field sketching is more than simply planning for a future work or keeping your drawing hand in practice. It is more even than learning to see. It is learning, period" (Johnson, 1997). To enhance student observational skills, assignments were aimed at increasing the student's ability to "see" with multiple senses. Using cues and subjects from their natural surroundings, students were encouraged to start putting their ideas down on paperwithout concern for their skills. Easing students into drawing exercises allowed them to become comfortable with their efforts and instructor feedback. Skills were interjected casually though brief lectures and/or demonstrations, and students were given time to practice and build upon a foundation-progressing to respectable levels of field sketching abilities. "Landscape drawing is not the reproduction of nature. It is an expression of the emotions, sensations, and feelings that the landscape impresses on the artist" (Sullivan, 2004).

The field sketching course first focused on examining the built and natural landscapes. For example, the initial field sketching assignment was an observational challenge to find an object in the outdoor environmentsomething simple like an individual flower, a statue, or a leaf. Students were told to sit comfortably about $6 \mathrm{ft}$ $(1.8 \mathrm{~m})$ away from the object and completely focus, while ignoring everything else in their surroundings. Students were coached to exhaust their observation, noting mentally (but not writing or drawing) the light, shape, shadows, colors, lines, textures, and form of their object. After $15 \mathrm{~min}$ of observation from a single vantage point, students were asked to move to another vantage point and repeat the process, after which, students opened their sketchbooks, and described in writing what they viewed and observed. This was followed by $5 \mathrm{~min}$ of sketching their objects. The value of this exercise is to ease students into the idea of keen observation. Students noted that they began to see things they did not notice on first glance, as evidenced by one student who noticed that the longer she looked at the object, the more she understood what she wanted to draw.

In another observation enhancement exercise, small groups went outside to various vantage points in Rio de Janeiro. Each group member wrote one sentence describing the view, or an element of the view, from his or her position, after which each group member wrote a sentence, and passed it to another group member, who added another sentence to further define the view. The groups then convened to read these sentences out loud and students enthusiastically embraced this exercise. It created positive energy, excitement, and a sense of pride in the results (Table 4). Self analysis of this writing assignment took the form of discussion about the words used to describe the landscape, and how the exercise helped them relate to the sense of place, the surrounding architecture, the climate, the landscape, and the time of day. Several students expressed a better sense of perception.

One of our most effective exercises took place in the Amazon forest at the INPA research station, where students initially took a walk and photographed the area. The next day, the students took a similar walk, without access to cameras and were asked to find 10 items of interest to sketch and describe. In a later debriefing session, most students were surprised at their new focused ability to observe and record details otherwise lost when they relied on photographs for documentation.

ENHANCING REFLECTION. Unstructured reflective journaling in these programs can be a challenge to enforce and grade (M.W. Rieger, personal communication). Structured, reflective journal questions were assigned periodically throughout the program (about one per day), with the intent to encourage students to think more deeply about the program and their experiences. Connective thinking was encouraged by the question "How would you describe the Panatanal to a group of 8th grade students?" or "Compare Manaus and Brasilia." To gauge students' 
Table 4. Results of an observational exercise conducted during "Landscape Exploration of Brazil" study abroad program. The first sentence was written by a student and subsequent sentences were added as students passed around a tablet. The sentences describe their observations of the Copacobana from the hotel rooftop.

\begin{tabular}{|c|c|}
\hline Student no. & Student observation \\
\hline 1 & $\begin{array}{l}\text { The geometric forms of the tiles make the crosswalks and stoplights } \\
\text { seem like part of the design. }\end{array}$ \\
\hline 2 & $\begin{array}{l}\text { Agreed!! In comparison with a typical street setting where there is an } \\
\text { obvious break, the use of the forms allows for more of a connection. }\end{array}$ \\
\hline 3 & The painted curb disrupts the pattern but still has very precise lines. \\
\hline 4 & $\begin{array}{l}\text { The waves are continued somewhat on the building side but not to the } \\
\text { extent of the beach side. }\end{array}$ \\
\hline 5 & There are a lot of shapes, mainly waves and squares. \\
\hline 6 & The palm trees on the beach look organized and scattered at the same time. \\
\hline 7 & Yes! The randomness is not at all messy. \\
\hline 8 & $\begin{array}{l}\text { It is also interesting how the beach is swept in geometrical patterns matching } \\
\text { the tiles. }\end{array}$ \\
\hline 9 & Birds in flight, now they must really have the best view! \\
\hline
\end{tabular}

reactions to assignments, "How did you feel about the Andy Goldsworthy assignment from the moment it was assigned to completion?" was posed. Journal responses indicated that the assignment seemed daunting when assigned but was fun to complete.

The faculty directors periodically collected the sketchbooks to control for completion of assigned questions. There were a total of 17 reflective journal questions during the monthlong visit. While some students kept up with their journal daily, others waited until due dates to complete their entries, minimizing the reflective nature of the assignments. Faculty directors should allow time during the structured day for students to work on their journals. Students need different assignments based on their different learning styles (Bean, 2001). "Sensing types, for example, want writing assignments with very detailed instructions and guidelines ...in contrast, intuitive types rebel against prescribed patterns and like open-ended assignments that give them room for their own unique or creative personal touches." Reflective journal questions should range from structured to open-ended, providing optimal learning opportunities for students in every learning category.

IFAT TECHNIQUE. When visiting a site, participating in an activity, reading a paper or hearing a lecture, each individual notices different details in different way, especially during a study abroad program. It is important to talk about these differences. The IFAT, developed by Michael Epstein, is a tool that facilitates student discussion (Epstein et al., 2002).

The IFAT is formatted as an answer form for multiple choice tests where the answer choices are covered by a scratch-off surface. For each question, the student scratches off the coating of their selected choice. If the choice is correct, a star appears in the box and the student goes on to the next item. If the student's choice is incorrect, a blank space appears. The student continues to scratch off choices until the star is found (DiBattista, 2001). DiBattista, who uses the IFAT form in psychology classes at Brock University, lists three pedagogical benefits. First, it provides immediate rather than delayed feedback. Second, the feedback is corrective, allowing students to learn the correct answer to every item before they move on. Third, because students can still earn points even if their first attempt is not correct, they are rewarded for their proximate knowledge of the correct answer (DiBattista, 2001). Students learn more when they use the IFAT form rather than standard Scranton multiple-choice test answer forms (Epstein et al., 2002).

The program used the IFAT form for quizzes that were administered to measure students' cognition of reading assignments and study abroad experiences. At first, simple multiple-choice quizzes with four questions were answered individually by students on scrap paper. In groups of four, students discussed the answers to each question and selected a group answer. Heated discussion of the correct answer often arises with students providing supporting detail as to why the answer they have chosen is correct. Once they reach consensus, they scratch off the IFAT form and are rewarded by immediate feedback. It is fascinating to hear the discussion that occurs as group members try to sway the group to select the answer he or she believes to be correct. This simple form and testing procedure elicits opinions and perspectives from each student and enhances learning.

Culminating Project. In PLSC 267 , teams of students were required to apply their observations and ideas formed during the program by selecting and developing a design proposal for a public space in Rio de Janeiro. Project site selection began with an observational exercise consisting of a guided walk in which students were asked to closely observe the landscape from the Jardim Botanico to the beach. Following the walk, students were given time in a classroom in the Jardim Botanico to create a graphic impression of what they had found most engaging about the walk. Students were then asked to present each other's drawings to the group as an exercise in understanding and translating graphic ideas into oral communication.

Through a reflective journal exercise, students were asked to identify environmental and social issues they observed in Rio de Janeiro. These included concern for the dramatic division of wealth, interest and concern for animals, and ways to enable the people in Rio de Janeiro to earn a livelihood using skills and talents they already possess. Individuals then shared these issues within their teams and each team selected an issue they sought to address through their design proposal. Due to travel logistics, most of the work on this culminating project (selecting the final site, observing and measuring the site to create a base plan, and developing ideas into design proposals) was completed in the last few days of the program. Students (44\%), however, wanted more time to complete the project (Table 2). Major projects should be introduced earlier in the program. Additionally, a series of smaller, cumulative design challenges should be used throughout the program to help teams develop a 
body of work that culminates in their final design proposal.

Cultural EXPERIENCES. In study abroad programs, there is a tendency to categorize experiences as part of the curriculum or as cultural excursions. Some students perceived a lack of connection between class activities and cultural learning (Table $3)$. While the program included visits to a soccer match, a samba club, a local flea market, and a variety of other cultural venues, these experiences were not perceived by students as "part" of the course content. This discrepancy could be resolved with structured class discussion of each cultural experience followed by a student assignment to represent that experience and the way it related to the curriculum in a student blog entry. Asking students to reflect on their cultural experiences throughout the program and incorporating a final assignment would make those experiences more relevant. Each student could be asked to select the cultural experience that meant the most to them and explain how that experience exemplified Brazilian culture.

Changes based on Qualitative EVALUATION. Based on the verbal feedback from the students, the online student evaluation of the program, and instructor experiences, several changes to the Brazil Study Abroad program have been planned.

1. Ask questions in a screening interview that ascertain students' flexibility and willingness to handle unknowns. For example:

You arrive back to your hotel room to find that the sink only gives you cold water. What will you do?

You understand the nature of a study abroad program is that we are unable to tell you details about each day and things may change at the last minute. How do you handle not knowing what your next move will be?

2. Limit required supplies so they can be easily carried on a daily basis.

3 . Present assignments to students in advance (predeparture) so that students can budget time accordingly.

4. Focus less on traditional lectures and more on discussion exercises and challenges that actively engage students. Instead of lecturing on culture (music, art, food, and dance), form small groups that each investigate a cultural topic and present a culminating activity related to their topic to the rest of the group.

5 . Hone presentation skills by requiring students to make two final project presentations-one to an audience in the study abroad setting and a second to an audience of university peers. This challenges students to consider multiple audiences and provides an opportunity to share experiences with the broader university community.

Teachers are often guilty of assuming that exposure equals learning. In fact, students, particularly at the undergraduate level, may require detailed explanations, structured discussions, specific assignments, structured opportunities for reflection, and guidance and critique to transform the information they encounter into content they understand. An effective study abroad program not only exposes students to unique experiences, but also helps students use those experiences to change their perspectives and understanding. Because of the variety of human learning styles, it is important to offer a range of educational activities so that all students have an opportunity to respond favorably. Of the many experiences and suggestions covered in this article, we hope some will help faculty enhance learning in future study abroad programs.

\section{Literature cited}

Andrews, D.C. and B. Henze. 2009. Teaching technical communication to American students in a study abroad program. Business Communication Quarterly $72: 5-20$.

Bean, J.C. 2001. Engaging ideas: The professor's guide to integrating writing, critical thinking, and active learning in the classroom. Jossey-Bass, San Francisco.

DiBattista, D. 2001. IFAT: If at first you don't succeed ... try, try again. Brock Teaching 1:2.

Epstein, M.L., A.D. Lazarus, T.B. Calvano, K.A. Matthews, R.A. Hendel, and B.B. Epstein. 2002. Immediate feedback assessment technique promotes learning and corrects inaccurate first responses. Psychol. Rec. 52:187-201.

Johnson, C. 1997. The Sierra Club guide to sketching in nature. Sierra Club Books, San Francisco.

Kozlek, B. 2008. From Utah: Blogs for enhancing student learning. 16 Aug. 2008. <http://www.personal.psu.edu/ bak147/blogs/brad/2008/08/fromutah-blogs-for-enhancing.html>.

Landscape Exploration of Brazil. 2008. Paisagens Brasileiras. 16 Aug. 2008. $<$ http://landscapesofbrazil.blogspot. $\operatorname{com} />$.

McIntyre, L. 2006. Art meets nature at Pierce's Woods. Landscape Architecture 96:90-94.

Montrose, L. 2002. International study and experiential learning: The academic context. Frontiers (Boulder) 8:1-15.

Pyle, R.M. 1993. The thunder tree: Lessons from an urban wildland. Lyons Press, New York.

Sullivan, C. 2004. Drawing the landscape. Wiley, Hoboken, NJ. 